2nd International Conference on Ultrafine Grained \&

Nanostructured Materials (UFGNSM)

International Journal of Modern Physics: Conference Series

Vol. 5 (2012) 257-262

(C) World Scientific Publishing Company

DOI: $10.1142 / \mathrm{S} 2010194512002103$

\title{
EFFECT OF GELATIN AMOUNT ON PROPERTIES OF NANO-BCP/GEL SCAFFOLDS
}

\author{
LEILA BAKHTIARI \\ Department of material engineering, Iran University of Science and Technology \\ Tehran, Narmak, 16844, Iran \\ leilabakhtiari@metaleng.iust.ac.ir \\ SEYED MOHAMAD HOSSAINALIPOUR, HAMID REZA REZAIE \\ Department of material engineering, Iran University of Science and Technology \\ Tehran, Narmak, 16844, Iran \\ mhossainalipour@iust.ac.ir,hrezaie@iust.ac.ir
}

\begin{abstract}
Biodegradable polymers and bioactive ceramics are being combined in a variety of composite materials for tissue engineering scaffolds. Porous nano-biphasic calcium phosphate/gelatin structure was prepared by freeze-drying method. Pre-pores were created by using naphthalene with different particle sizes. Stabilization of gelatin network matrix carried out by EDC (N-(3-dimethyl aminopropyl)- $\mathrm{N}^{\prime}$-ethyl carbodiimide hydrochloride) with cross-linking method. Three different amount of gelatin $(2,6$ and $10 \mathrm{mg} / \mathrm{ml})$ solution were used to study the effect of gelatin amount on properties of the scaffold. Microstructural properties of scaffolds were characterized by scanning electron microscopy (SEM). Fourier transform infrared spectroscopy (FTIR) was used to determine the chemical composition of scaffold. Also the morphology and bending strength were investigated.
\end{abstract}

Keywords: Bone tissue engineering; Scaffold; Nano BCP; Gelatin; Freeze drying.

\section{Introduction}

"Tissue engineering is a new and exciting technique which has the potential to create tissues and organs. It involves the in vitro seeding and attachment of human cells onto a scaffold. These cells then proliferate, migrate and differentiate into the specific tissue while secreting the extracellular matrix components required creating the tissue." "It involves the expansion of osteogenic cells from a biopsy, followed by the culturing of them in temporary three-dimensional scaffolds to form the new organ or tissue. ${ }^{2,}$

"Many suitable materials have been used as scaffolds, including bioactive ceramic (e.g. hydroxy apatite (HA), TCP, BCP, bioactive glass (BG)) and polymers such as polylactic acid (PLA), polyglycolic acid (PGA) and their copolymers. ${ }^{3-6,}$

"Nowadays, biphasic calcium phosphates (BCP) ceramics (HA/B-TCP) developed. This matter can be explained by effective role of biphasic calcium phosphates in bone repair and regeneration than pure HA or B-TCP, and their controllable degradation rate.",

"The collagen-based gelatin has a high degree of biological functional groups, and has some potential for applications in tissue scaffolds. In practical terms, gelatin is 
currently used in pharmaceuticals, wound dressings and adhesives in clinics due to its good cell viability and lack of antigenicity. Its shape availability and cost-efficiency can facilitate the selectivity and mass-producibility. ${ }^{8,9}$,

Actually, the natural bone is mainly composed of BCP and gelatin (GEL), where BCP is deposited on the gelatin matrix in a regular manner.

In this study, nano-BCP/GEL porous scaffolds with different amount of gelatin were investigated.

\section{Experimental procedures}

\subsection{Scaffold fabrication}

The nano-sized BCP particles with 70\% hydroxy apatite (HA) and 30\% B-tricalcium phosphate ( $($-TCP) were prepared by precipitation method. Calcium hydroxide (Ca $(\mathrm{OH})_{2}$, Acros Organics, $98 \%$ purity) and orthophosphoric acid $\left(\mathrm{H}_{3} \mathrm{PO}_{4}\right.$, Merck, $85 \%$ purity) were used as the starting materials. Calcium hydroxide solution in distilled water, stirred in magnet stirrer for $1 \mathrm{~h}$, to obtain homogen suspension. $1 \mathrm{M}$ orthophosphoric acid solution was added with $15-20 \mathrm{ml} / \mathrm{min}$ rate to calcium hydroxide suspension. For controlling the $\mathrm{pH}$ of the solution in the range of $10-12$, hydrogen nitride $\left(\mathrm{NH}_{3}\right.$, Merck) was used. To obtain high homogeneity and gelation, the prepared sol was aged in stirrer for $2 \mathrm{~h}$ and then at room temperature $\left(25^{\circ} \mathrm{C}\right)$ for $24 \mathrm{~h}$. The gel was dried at $110^{\circ} \mathrm{C}$ for $48 \mathrm{~h}$ and after that it was calcinated at $700^{\circ} \mathrm{C}$ for $2 \mathrm{~h}$ to achieve $70 \% \mathrm{HA}$ and $30 \% \mathrm{~B}$-TCP (BCP).

Naphthalene powder was used as porogen with three different particle sizes. Naphthalene and BCP powder were mixed with a ratio of 2:3. To supply adhesion, the prepared batch and 5\% poly vinyl alcohol (PVA, Acros Organics, 88\% purity) solution were mixed (weight ratio of 10:1). The batch was aged for $24 \mathrm{~h}$ and prepared powder was pressed with uniaxial pressing with $50 \mathrm{MPa}$ pressure and then sintered at $1400^{\circ} \mathrm{C}$ for $1 \mathrm{~h}$ with a heating rate of $10^{\circ} \mathrm{C} / \mathrm{min}$.

Thereafter, BCP scaffold was immersed in gelatin from bovine skin type B (SigmaAldrich) in distilled water (A: 2, B: 6 and $\mathrm{C}: 10 \mathrm{mg} / \mathrm{ml}$ and $\mathrm{pH} 7$ ) for $4 \mathrm{~h}$, so that pores could be filled with the gelatin solution. BCP scaffold was then kept in freezer (Ultra Low Temperature Freezer, New Brunswick Scientific) at $-70^{\circ} \mathrm{C}$ for $18 \mathrm{~h}$ and then freezedried in freeze-dryer (Christ Alpha 2-4, German) at $-80^{\circ} \mathrm{C}$ for $7 \mathrm{~h}$ to form a gelatin network matrix on the pore and surface of the scaffold. After that, the gelatin network matrix immersed in 1\% EDC (N-(3-dimethyl aminopropyl)- $\mathrm{N}^{\prime}$-ethyl carbodiimide hydrochloride, Merck) solution in distilled water for cross linking and confirming the gelatin. Then the Samples were washed with a $0.1 \mathrm{M} \mathrm{Na} \mathrm{NPO}_{4} \cdot 12 \mathrm{H}_{2} \mathrm{O}$ (Merck) and deionized water. Finally the Samples dried in air and again freeze dried at $-80^{\circ} \mathrm{C}$ for $4 \mathrm{~h}$.

\subsection{Scaffold characterization}

Scanning electron microscopy (SEM: XL30, Philips) was used to observe pores of the scaffold. The samples were sputter-coated with a layer of gold for observation at $25 \mathrm{kv}$. 
Fourier-Transformed Infrared spectroscopy (FTIR: Shimadzu, 8400s) was used to determine the chemical bound formation of scaffolds. Mechanical behavior of scaffolds was examined with 3 point bending strength.

\section{Results and discussion}

\subsection{Mechanical behavior}

By increasing gelatin amount in nano-BCP/gelatin scaffold, bending strength was increased (Table 1). As results show, bending strength before freezing and freeze-drying is less than the samples after freeze-drying. By freezing the immersed samples in gelatin solution and after that freeze-drying them, composite formation was created.

It could be explained by increasing gelatin content in scaffold structure and making high bound formation.

Table 1. 3 point bendig strenght of scaffolds.

\begin{tabular}{ll}
\hline Kind of scaffold & Bending strength(MPa) \\
\hline Sample before freeze-drying & 1.88 \\
$\mathrm{~A}(2 \mathrm{mg} / \mathrm{ml}$ gelatin $)$ & 1.91 \\
$\mathrm{~B}(6 \mathrm{mg} / \mathrm{ml}$ gelatin $)$ & 2.10 \\
$\mathrm{C}(10 \mathrm{mg} / \mathrm{ml}$ gelatin $)$ & 2.46 \\
\hline
\end{tabular}

\subsection{SEM observations}

Fig. 1 shows the microstructure of the BCP powder. As this figure shows the size of the particles are in the range of $20-50 \mathrm{~nm}$ with needle-like shapes.

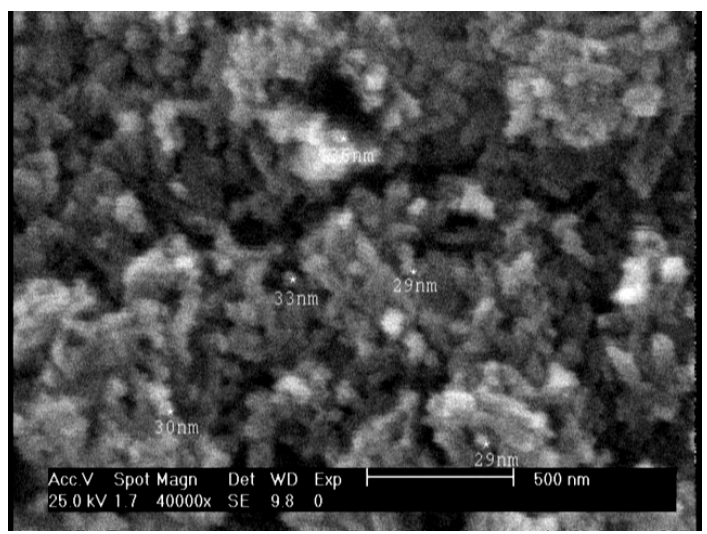

Fig. 1. SEM micrograph of the BCP powder. 
SEM observation of cross section of A, B and C scaffolds are show in Fig. 2. As this figure show the pores are interconnected as natural bone structure. Measuring the average pore sizes in different samples revealed that pore sizes increased by increasing gelatin concentration.
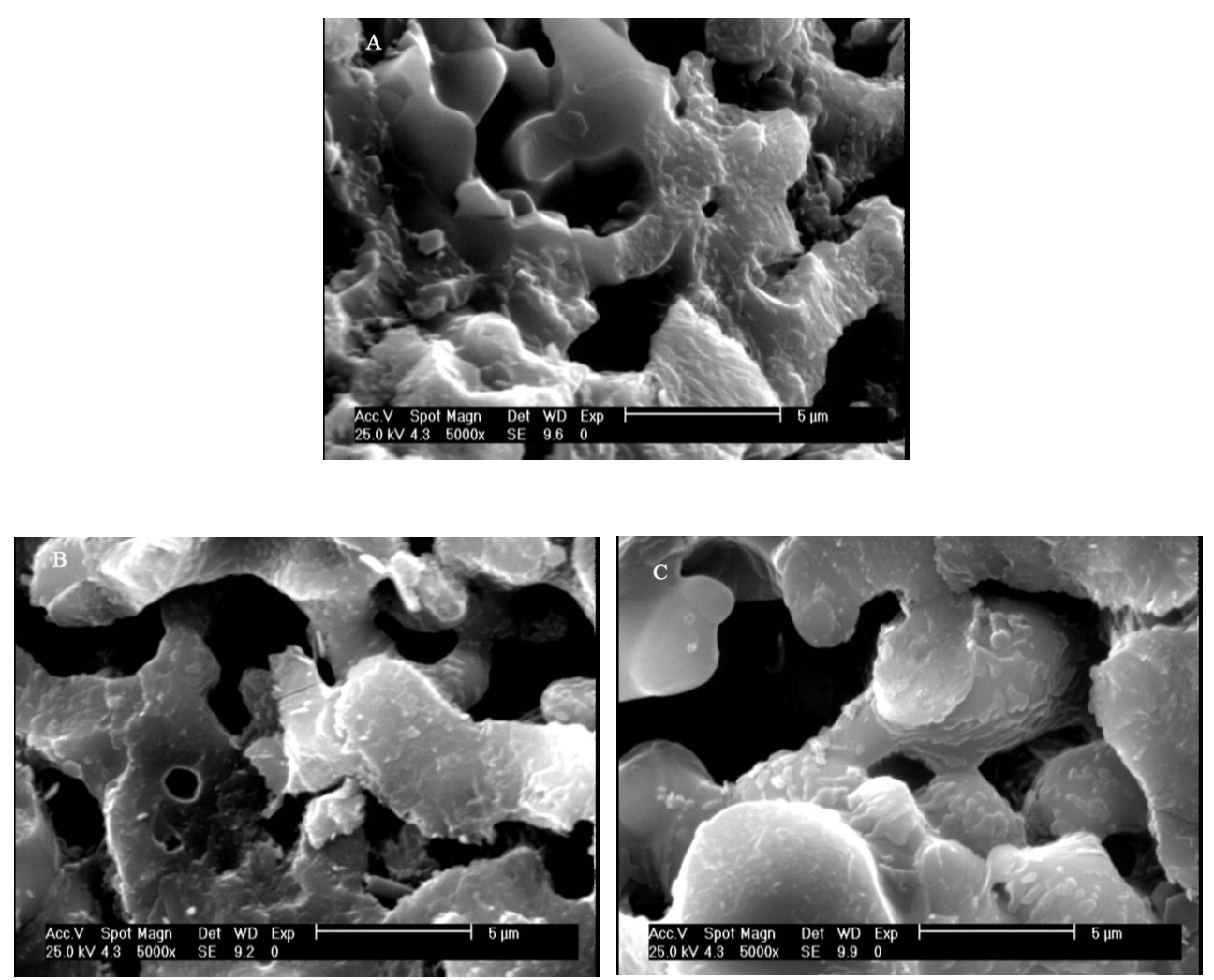

Fig. 2. SEM images of A, B and C samples (Cross section).

\subsection{FTIR results}

For further illustration of chemical bound formation, fourier transform infrared spectroscopy (FTIR) was used. Fig. 3 shows FTIR spectras of scaffolds with different gelatin amounts (A, B and C). As results show, by increasing gelatin amount from A to C scaffolds, intensity of amid peaks get softer. "Bands at 1700 and $1200 \mathrm{Cm}^{-1}$ in BCP/GEL scaffold associated with formation of amide I and II due to adding gelatin in BCP/GEL spectra. ${ }^{10,}$ In different scaffolds $\mathrm{Po}_{4}{ }^{-3}$ bands were found in same wave numbers. 


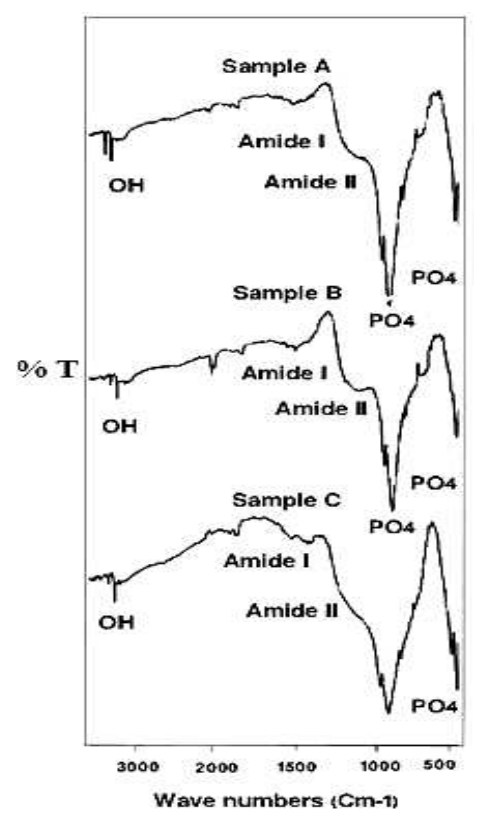

Fig. 3. FTIR spectras of A, B and C samples.

\section{Conclusions}

Gelatin/BCP nanocomposite scaffolds which prepared by freeze-drying method had a well developed pore structure with adequate mechanical properties. Nanoscale $\beta$-TCP exhibits significant biological affinity and activity and responds very well to the physiological environments. Also owing to its slow degradation characteristic, the porous $\beta$-TCP is regarded as an ideal material for bone substitutes that should degrade by advancing bone growth.

The use of BCP scaffold as a mechanical skeleton facilitates the formation of the collagen network matrix into desired shapes and gives it good mechanical properties. The crosslinked gelatin network matrix and as the primary components of bone tissue will provide good cell interaction and osteoconductivity.

In this study, scaffolds of BCP/GEL with three different amount of gelatin to achieve optimum amount of polymer were compared. These comparisons suggest that the $\mathrm{BCP} / \mathrm{GEL}$ scaffold nanocomposite have high potential for use as a hard tissue with high porous structure and good mechanical behavior.

\section{Acknowledgments}

The authors thank the Iran University of Science and Technology (IUST) for their supports. 


\section{References}

1. E. Sachlos, J.T. Czernuszka, European Cells and Materials Vol. 5, 29-40 (2003).

2. M. Kellomaki, H. Niiranen, K. Puumanen, N. Ashammakhi, T. Waris, P. Tormala, Biomaterials 21, 2495- 2505 (2000).

3. Y. Zhang, M. Zhang: J. Biomed. Mater. Res 55, 304-312 (2001).

4. R.A. Quirk, M.C. Davies, S.J.B. Tendler, K.M. Shakesheff, Macromolecules 33, 158-160 (2000).

5. L.D. Shea, D. Wang, R.T. Franceschi, D.J. Mooney, Tissue Eng 6, 605-617 (2000).

6. A.S. Goldstein, T.M. Juarez, C.D. Helmke, M.C. Gustin, A.G. Mikos, Biomaterials 22, 12791288 (2000).

7. H. R.R. Ramay, M. Zhang, Biomaterials 25, 5171-5180 (2004).

8. Word AG, Courts A. The science and technology of gelatin, 1977, London, Academic Press.

9. E. Cenni, G. Ciapetti, S. Stea, A. Corradini, F. Carozzi, J. Biomater. Sci. Polym Ed 11, 68599 (2000).

10. M. Chul Chang, C-Chang Ko, W. H. Douglas, Biomaterials 24, 3087-3094 (2003). 